\title{
A molar masquerading as an ectopic pregnancy in the early first trimester: a salutary lesson
}

This article was published in the following Dove Press journal:

International Journal of Women's Health

2I August 2012

Number of times this article has been viewed

\author{
Abha Govind' \\ Nisha Lakhi² \\ 'Department of Obstetrics and \\ Gynaecology, North Middlesex \\ University Hospital, London, UK; \\ ${ }^{2}$ Department of Obstetrics and \\ Gynecology, Richmond University \\ Medical Center, Staten Island, New \\ York, NY, USA
}

\begin{abstract}
The authors report a case in which a molar pregnancy was mistaken for an ectopic pregnancy in the early first trimester. This confusion delayed diagnosis and caused distress; follow-up led to the final diagnosis of complete hydatidiform mole. Correct preoperative diagnosis of molar pregnancy by ultrasound in early pregnancy may be tricky. It is important to obtain histological evidence to make the final diagnosis of gestational trophoblastic disease. While relatively rare, consideration of molar pregnancy in the differential diagnosis of early pregnancy loss may avoid unnecessary distress.
\end{abstract}

Keywords: first trimester ultrasound, molar pregnancy, gestational trophoblastic disease, complete hydatidiform mole, diagnosis

\section{Introduction}

A complete hydatidiform mole appears as a homogeneously echogenic endometrial mass on scan, without identifiable fetal parts. In the early first trimester a complete hydatidiform mole may appear like a thickened endometrium, raising suspicion of an ectopic pregnancy. ${ }^{1}$ A few weeks later, appearances can be confused with retained products of conception. The case presented here illustrates how ultrasound can be misleading in the early first trimester.

\section{Case report}

A 41-year-old parous woman presented to the early pregnancy assessment unit in the United Kingdom on day 0 with a history of 7 weeks of amenorrhea, lower abdominal pain, and brownish vaginal bleeding. A transvaginal ultrasound showed an empty uterus with a thickened endometrium. No adnexal mass or free fluid was seen. Two readings of serum beta human chorionic gonadotropin ( $\beta$-hCG) 48 hours apart measured 1900 and 1998 IU/L. An ectopic pregnancy was suspected in view of the lower abdominal pain. Surgical treatment in the form of a diagnostic laparoscopy that would then proceed to salpingectomy was discussed. The patient agreed, as she felt her family was complete and she also wished to be sterilized. She consented to removal of the affected fallopian tube and clipping or removal of the other as part of the treatment for ectopic pregnancy and as the method for sterilization. Laparoscopy revealed suspicion of a left ovarian ectopic pregnancy, as the ovary appeared enlarged and bluish. An ovarian biopsy was taken and the patient underwent bilateral salpingectomy as per her request for permanent sterilization. The patient was discharged with a follow-up plan. Histology of the ovarian biopsy showed cystic corpus luteum. Both tubes showed nonspecific
Correspondence: Nisha A Lakhi Department of Obstetrics and Gynecology, Richmond University Medical Center, 355 Bard Avenue, Staten Island, New York, NY 10310, USA Emailnlakhi@yahoo.com 
salpingitis but no chorionic villi. The patient's $\beta$-hCG had risen to $5000 \mathrm{IU} / \mathrm{L}$ on day 21 and she reported slight vaginal bleeding. A repeat ultrasound showed retained products of conception $(15 \times 23 \mathrm{~mm})$, with no adnexal mass or free fluid (Figure 1). The patient chose conservative management for the incomplete miscarriage and was given a follow-up appointment.

At follow-up on day 27, a repeat ultrasound was suggestive of a molar pregnancy (Figure 2 ). The $\beta$-hCG value was now 10,000 IU/L.

The patient underwent surgical evacuation of retained products of conception. Histological examination of the uterine contents confirmed chorionic villi that appeared edematous and forming atypical trophoblastic proliferation. No fetal parts were seen. Histology confirmed a complete hydatidiform mole, with no evidence of choriocarcinoma. Weekly measurement of serum and urine $\beta$-hCG levels at the regional trophoblastic center was arranged. The urine $\beta$-hCG assays returned to $<2 \mathrm{IU} / \mathrm{L}$ by day 55 .

\section{Discussion}

The ability of the early first trimester ultrasound to detect molar pregnancy is not always straightforward. Ultrasound features of very early molar pregnancy can be nonspecific. Some can appear as a thickened endometrium and later may be confused with an incomplete miscarriage. ${ }^{1-3}$ The thickened endometrium, given the clinical and biochemical presentation, can be confused with an ectopic pregnancy, necessitating a laparoscopy.

The classic ultrasound findings of an enlarged uterus filled with amorphous echogenic material, possibly containing vesicles, are not visualized until the late first trimester or early second trimester. ${ }^{3}$ Without a high index of suspicion, a molar pregnancy can be mistaken for an ectopic pregnancy during early evaluation.

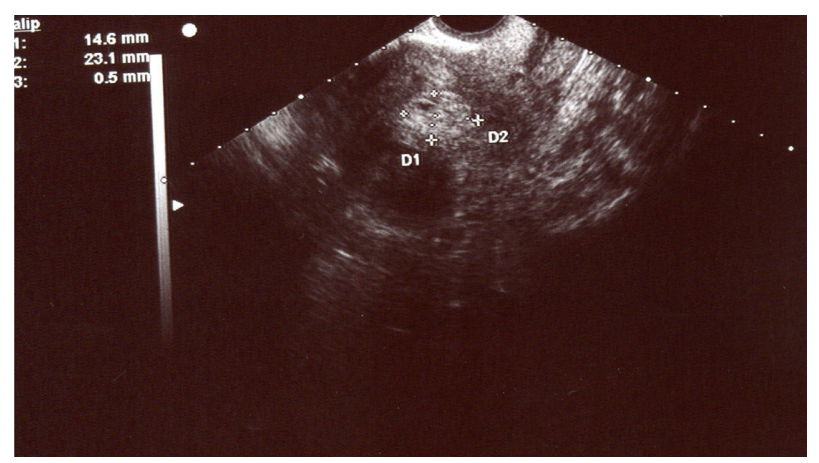

Figure I Transverse view at the fundus thought to be of retained products of conception (day 21 ).

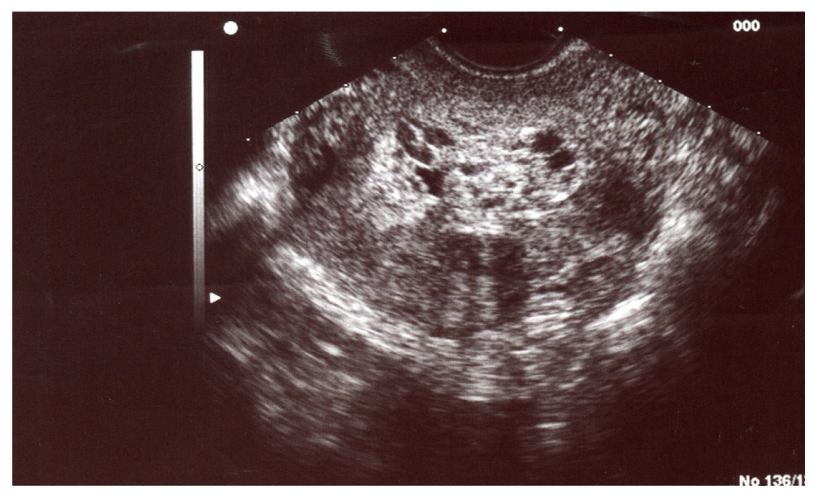

Figure 2 Scan appearance of molar pregnancy on day 27.

The overall sensitivity for the ultrasound diagnosis of molar pregnancies ranges from $50 \%$ to $86 \% .{ }^{4}$ This may be attributed to the histomorphic feature of the hydropic villi. In the first trimester, hydropic change is minimal and is likely to remain unnoticed. ${ }^{4}$

Several recent studies have highlighted the problem of ultrasound diagnosis of molar pregnancies. In a retrospective review of ultrasound and histological findings in 194 cases referred to the UK National Trophoblastic Disease Surveillance Centre with suspected molar pregnancies, Sebire et $\mathrm{al}^{2}$ showed that 131 (67\%) cases had an ultrasound diagnosis of miscarriage with no suspicion of molar pregnancy prior to evacuation of the uterus. The median gestational age at diagnosis was 10 weeks. Referral in these cases was made based on histological examination of products of conception. Sebire et $\mathrm{al}^{2}$ caution that even gross examination of products of conception is unreliable, as gross features described in later gestation, such as large vesicle-like villi with prominent cisterns, may not be apparent in cases examined in the first trimester.

Fowler et $\mathrm{al}^{3}$ have shown that routine pre-evacuation ultrasound examination of over 1000 cases of histologically confirmed molar pregnancies identified less than $50 \%$, the majority instead appearing as incomplete miscarriage. Detection rates of $35 \%-40 \%$ were found before 14 weeks' gestation, compared with $60 \%$ thereafter. The sensitivity, specificity, positive predictive value, and negative predictive value for routine pre-evacuation ultrasound for detection of any type of molar pregnancy were $44 \%, 74 \%, 88 \%$, and $23 \%$, respectively. Histopathology remains the current gold standard.

Lindholm and Flam ${ }^{5}$ conducted a retrospective review of elective terminations that had a confirmed pathological diagnosis of molar pregnancy and correlated this with initial clinical and ultrasound findings. The mean gestational age for the ultrasound scan was 12.4 weeks. It was found that the 
sonogram evaluation missed $16 \%$ of complete hydatidiform moles. Finally, Kirk et al $^{6}$ retrospectively assessed ultrasound findings in 90 women, 56 of whom had a complete mole suspected and 34 of whom were diagnosed by histology. The ultrasound findings in 26 of the 34 cases were initially described as miscarriage.

It is important to note that, just as ultrasound diagnosis can be difficult during the early first trimester, differential diagnosis between normal gestation, partial moles, and complete moles is still a challenge for pathologists. In early pregnancy, characteristic pathological features of molar pregnancy many not be readily apparent. Diagnosis based solely on morphology can be affected by interobserver variability. ${ }^{7}$ Molecular genotyping together with morphology can aid in diagnosis. ${ }^{7}$

There is no doubt that laparoscopy becomes necessary when the clinical picture makes one strongly suspect an ectopic pregnancy. In the case presented, a relatively low level of serum $\beta$-hCG compounded with the ultrasound appearance of a thickened endometrium and a laparoscopic suspicion of an ovarian ectopic pregnancy prevented performance of dilation and curettage at the same time as the laparoscopy. Histological examination of the uterine curettings may have avoided the second general anesthetic and prolonged follow-up that this patient required.

\section{Conclusion}

This case illustrates that the correct preoperative diagnosis of the molar pregnancy by ultrasound and pathological examination in early pregnancy may be tricky. It highlights the importance of combining ultrasound findings with pathological assessment to make the final diagnosis of gestational trophoblastic disease. While relatively rare, consideration of molar pregnancy in the differential diagnosis of early pregnancy loss may avoid unnecessary distress.

\section{Disclosure}

The authors report no conflicts of interest in this work.

\section{References}

1. Jain KA. Gestational throphoblastic disease: pictorial review. Ultrasound $Q$. 2005;21(4):245-253.

2. Sebire NJ, Rees H, Paradinas F, Seckl M, Newlands E. The diagnostic implications of routine ultrasound examination in histologically confirmed early molar pregnancies. Ultrasound Obstet Gynecol. 2001; 18(6):662-665.

3. Fowler DJ, Lindsay I, Seckl MJ, Sebire NJ. Routine pre-evacuation ultrasound diagnosis of hydatidiform mole: experience of more than 1000 cases from a regional referral center. Ultrasound Obstet Gynecol. 2006;27(1):56-60.

4. Alhamdan D, Bignardi T, Condous G. Recognising gestational trophoblastic disease. Best Pract Res Clin Obstet Gynaecol. 2009;23(4): 565-573.

5. Lindholm H, Flam F. The diagnosis of molar pregnancy by sonography and gross morphology. Acta Obstet Gynecol Scand. 1999;78(1):6-9.

6. Kirk E, Papageorghiou AT, Condous G, Bottomley C, Bourne T. The accuracy of first trimester ultrasound in the diagnosis of hydatidiform mole. Ultrasound Obstet Gynecol. 2007;29(1):70-75.

7. Vang R, Gupta M, Wu LS, et al. Diagnostic reproducibility of hydatidiform moles: ancillary techniques (p57 immunohistochemistry and molecular genotyping) improve morphologic diagnosis. Am J Surg Pathol. 2012;36(3):443-453.
International Journal of Women's Health

\section{Publish your work in this journal}

The International Journal of Women's Health is an international, peerreviewed open-access journal publishing original research, reports, reviews and commentaries on all aspects of women's healthcare including gynecology, obstetrics, and breast cancer. Subject areas include: Chronic conditions (migraine headaches, arthritis, osteoporosis);

\section{Dovepress}

Endocrine and autoimmune syndromes; Sexual and reproductive health; Psychological and psychosocial conditions. The manuscript management system is completely online and includes a very quick and fair peer-review system. Visit http://www.dovepress.com/ testimonials.php to read real quotes from published authors. 